\title{
Anesthesia at Remote Location An experience of Surkhet Health Camp
}

Bajracharya U*

Maintaining high standards of anesthesia care at the remote locations is a challenge. A legendary American anesthesiologist, Ralph Waters, opened his Downtown Anesthesia Clinic in Sioux City, lowa, as an example for the modern freestanding ambulatory surgical unit. This unit further developed with the establishment of the Society of Ambulatory Anesthesia (SAMBA). The ambulatory surgical unit may prototypically be hospital integrated, hospital based, freestanding or Office based.

The anesthetic implications of the patient's medical condition do not vary with anesthetizing locations, but the logistics in providing anesthesia services frequently differ.
Potential problems for the anesthesiologist providing care for patients in remote locations can be due to the physical layout of the facility, to unfamiliar or outdated anesthesia equipment, to the anesthetic implication of the procedure performed, to working with personnel who are less familiar with the anesthetic aspects of patient care in these settings, and to the remoteness from available help.

Thus, the lack of familiarity, combined with geographic remoteness from the surgical suite, may mean that less ancillary help will be available to the anesthesiologist.

On the day of arrival in Surkhet (4 Bde.) operation theatre (OT) members $(5+1)$, started preparing the OT, and this work was over by the next day noon.

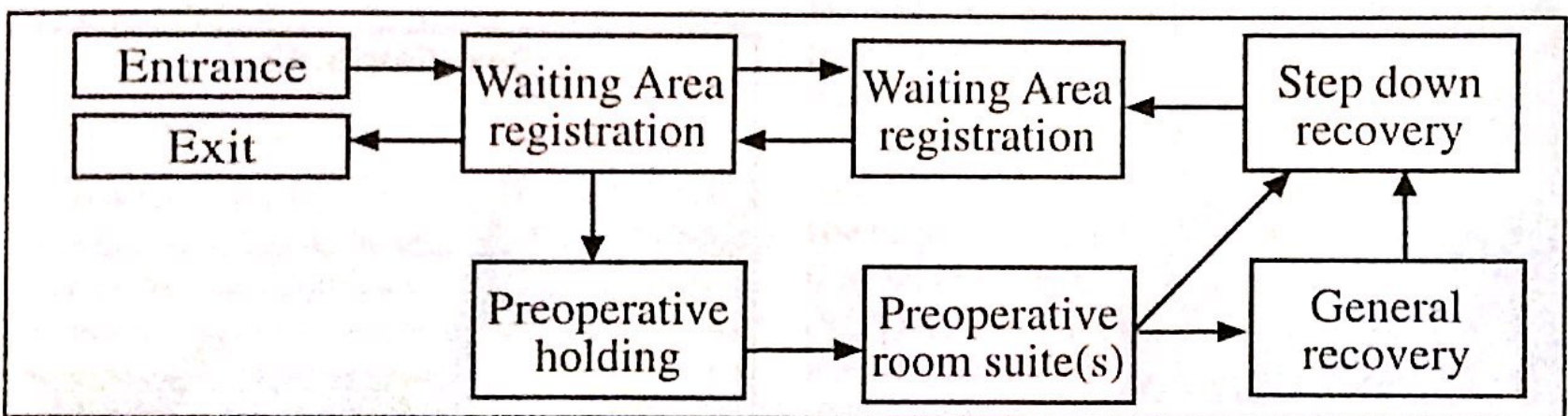

Figure 1: Showing Essential components related to patient flow in an ambulatory surgical unit

Physical constraints imposed by the environment, different paramedical personnel, and often a lack of the surgical suite challenge the anesthesiologist to tailor provision of anesthesia services to the special requirements posed by the situations.

The American Society of Anesthesiologists (ASA) 1994 guidelines for non-operating room anesthetizing locations include recommendations for (1) oxygen source, (2) suction, (3) scavenging, (4) necessary equipment, drugs, and monitors, (5) Electrical outlets, (6) illumination, (7) space, (8) emergency equipment, (9) communications, and (10) building and safety codes.

* Dr. Uday Bajracharya, MBBS, MD. Maj., Consultant Anacsthesiologist Shree Birendra Hospital, Chhauni
As soon as the surgeon arrived, surgery was started. Man power: Anesthesiologist \& Anesthesia assistant

Surgeon \& Surgical assistant

Scrub sister

Cleaner

POP unit: Sister for the daytime

Paramedics for the nighttime

Surgeons examined the patients in the OPD and sent them to the (OT). After a brief interview with the patients/ his parents and short physical examinations, patients were taken into the OT for surgery. Most of the time, request for blood tests and X-rays were not made. 


\begin{tabular}{|c|c|c|c|c|c|c|}
\hline S.N & \multicolumn{3}{|c|}{ Anaesthesia } & \multirow[t]{2}{*}{ Total } & Equipment & \multirow[b]{2}{*}{ 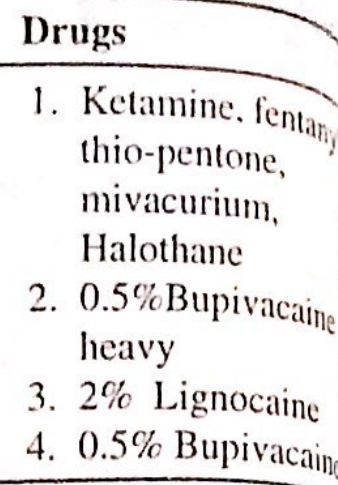 } \\
\hline 1 & GA & SA & $\begin{array}{l}\text { MAC } \\
\text { (Monitored } \\
\text { Anaesthetic } \\
\text { Care) }\end{array}$ & & $\begin{array}{l}\text { 1. } \mathrm{O}_{2} \text { Cylinder } \\
\text { ( } \mathrm{G} \& \text { E size) } \\
\text { 2. } \mathrm{O}_{2} \text { Flow meter } \\
\text { 3. TEC-3 vaporizer } \\
\text { 4. Bain Circuit/JR } \\
\text { circuit }\end{array}$ & \\
\hline & 31 & 4 & 52 & 85 & & \\
\hline \multicolumn{5}{|c|}{$\begin{array}{l}\text { Table I: Showing total surgery performed under different } \\
\text { anaesthesia with different equipments } \\
\text { Small children were anaesthetized on the lap of their } \\
\text { mothers by giving intramuscular Ketamine }(5 \mathrm{mg} / \\
\mathrm{kg} \text { ) and an IV cannula was inserted. Only one child } \\
\text { was intubated. Most of the children were maintained } \\
\text { with inhalation Halothane anacsihesia by means of }\end{array}$} & \multicolumn{2}{|c|}{ Patient distribution } \\
\hline
\end{tabular}

Face Mask and lackson Rees circurt. There was no

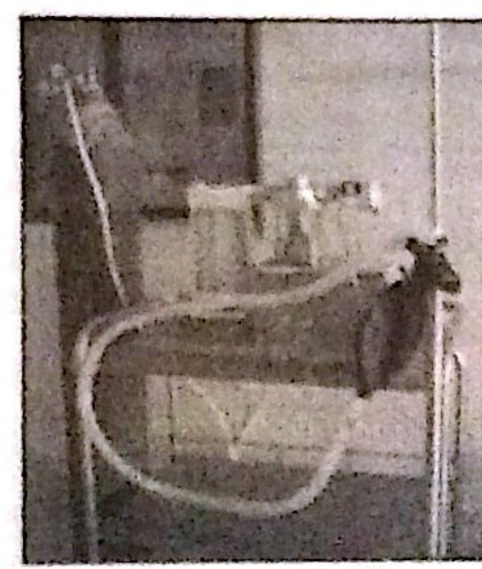

Fig 2: Fow meter with $\mathrm{O}_{2}$ cyitriter and TEC - 3 vaporrzer with Iain circuit critical event as such. But one child had URTI and there were a lol of nasopharyngeal secretions, which were removed after good suctions. Two patients had PDPH after $\mathrm{SA}$ in the post operative (POP) unit, as they did not obey the POP instructions. Four patients had a big

little problems post-operative nausea and vomiting (PONV). 4 patients underwent spinal anaesthesia without any intra-operative problems.

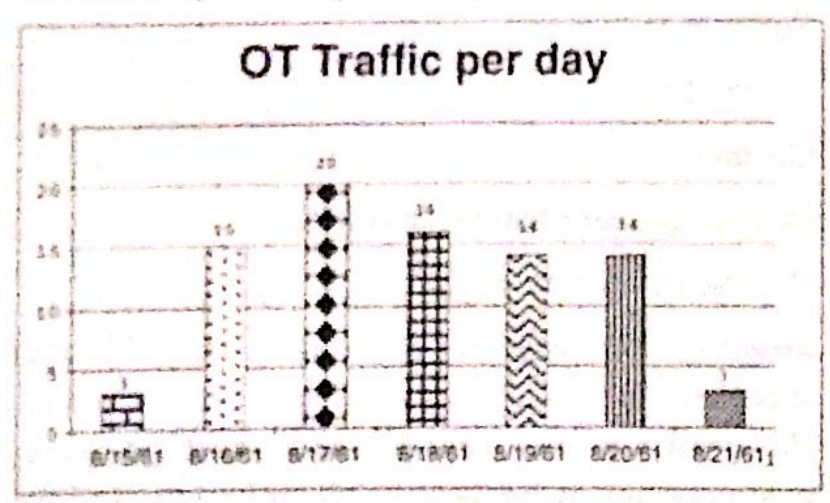

Fig. 3: Greph showing OT traffic per day at Surkhet Medical Camp

Fig. 4: Pie chart showing patient distribution at Surkhet Medic Camp

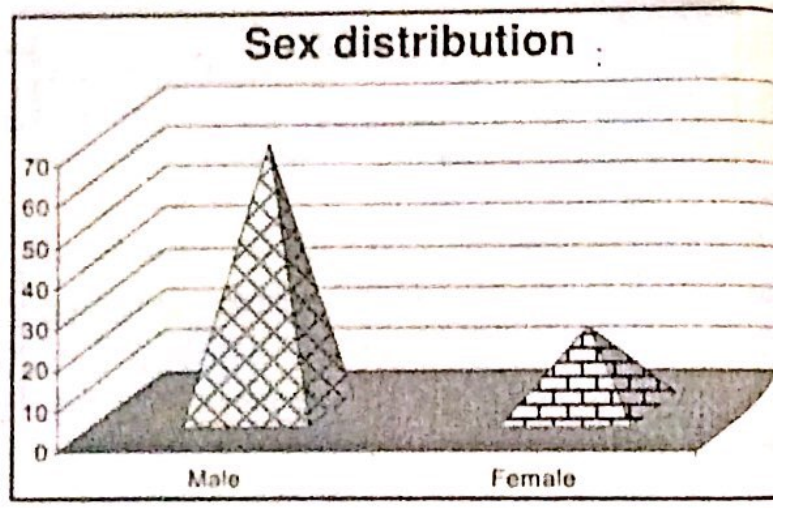

Fig. 5: Chart showing sex distribution at Surkhet Medical Car

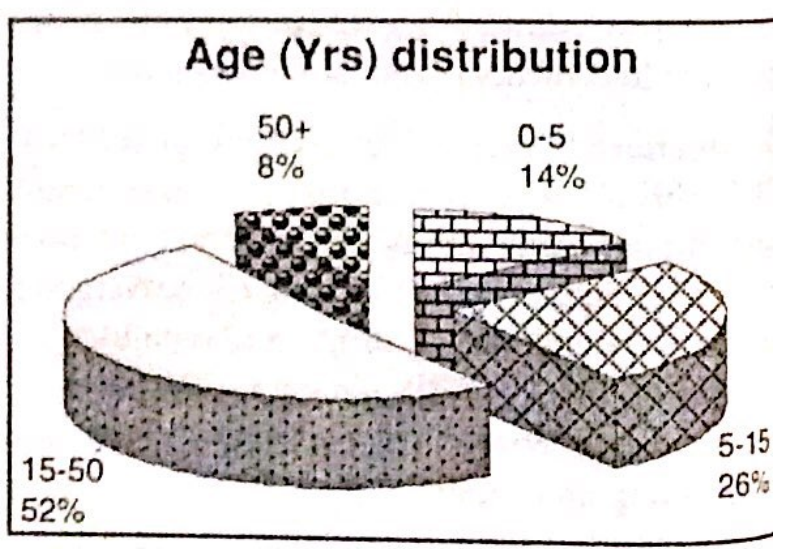

Fig. 6: Pic chant showing age (yrs) distribution at Surk! Medical Camp 


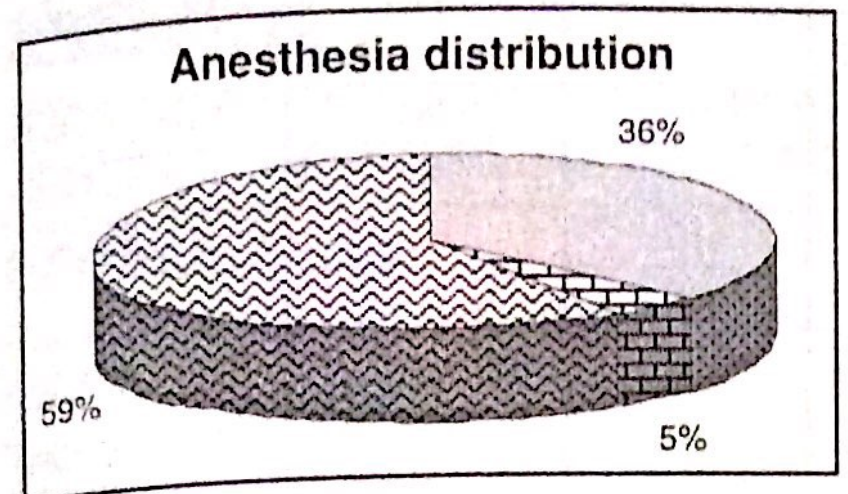

Fig. 7: Pic chart showing anaesthesia distribution at Surkhet Medical Camp

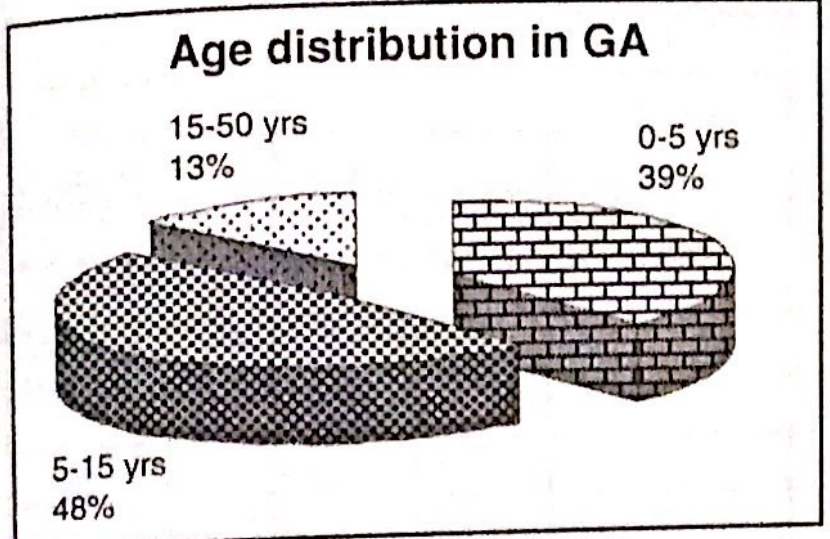

Fig. 8: Pie chart showing age distribution in GA at Surkhet Medical Camp

\section{Conclusion}

Ambulatory surgeries are to be continued. Standard of preparations are to be uplifted. For fast tracking after ambulatory surgeries, short acting drugs like propofol, fentanyl, mivacurium, vecuronium,

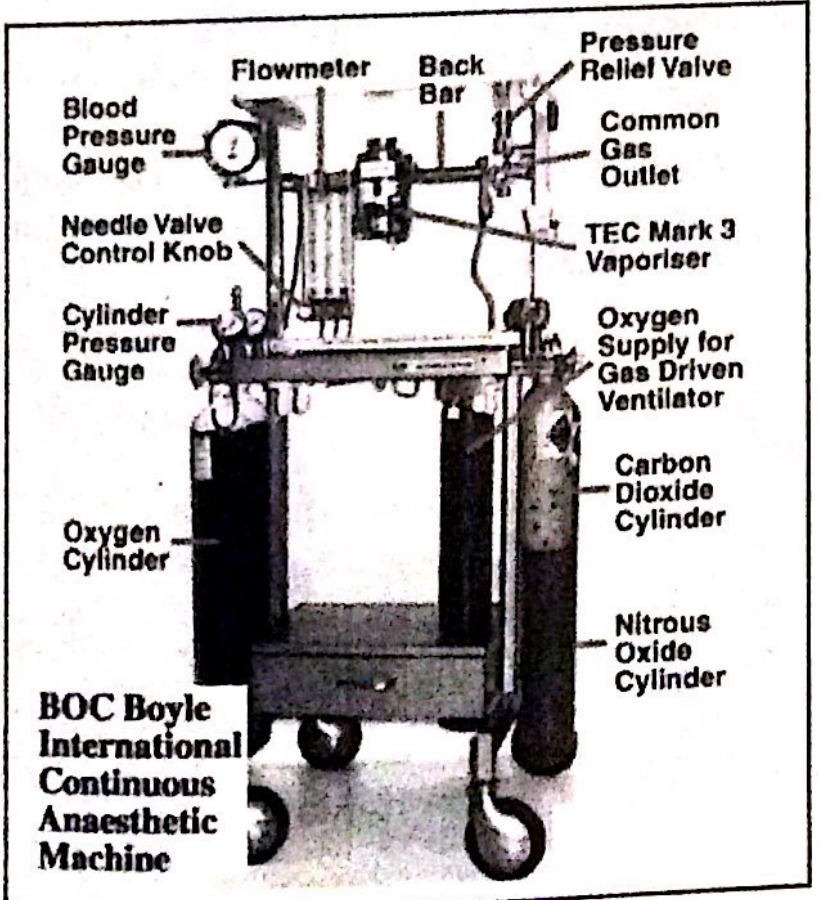

Fig 9: BOC Boyle International Continuous Anaesthetic Machine

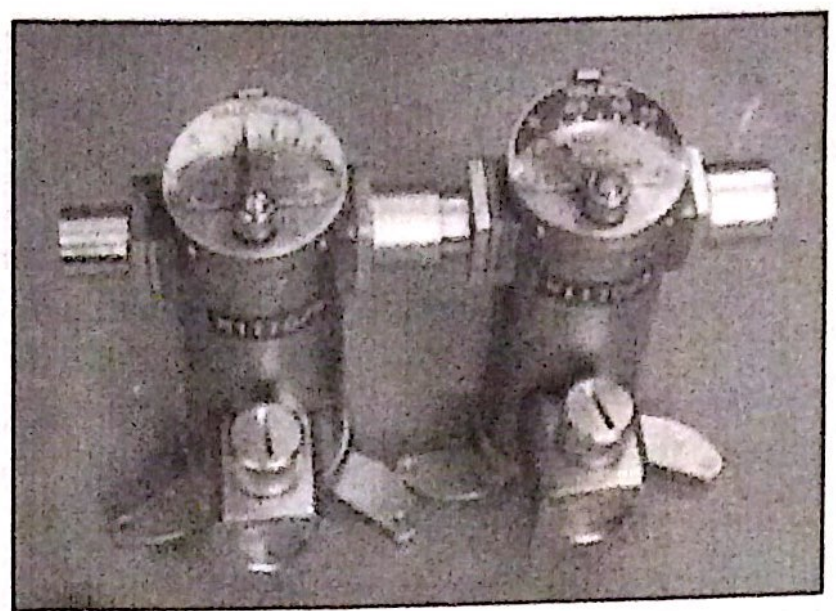

Fig 10: Showing Oxford miniature vaporizers-Triservice models

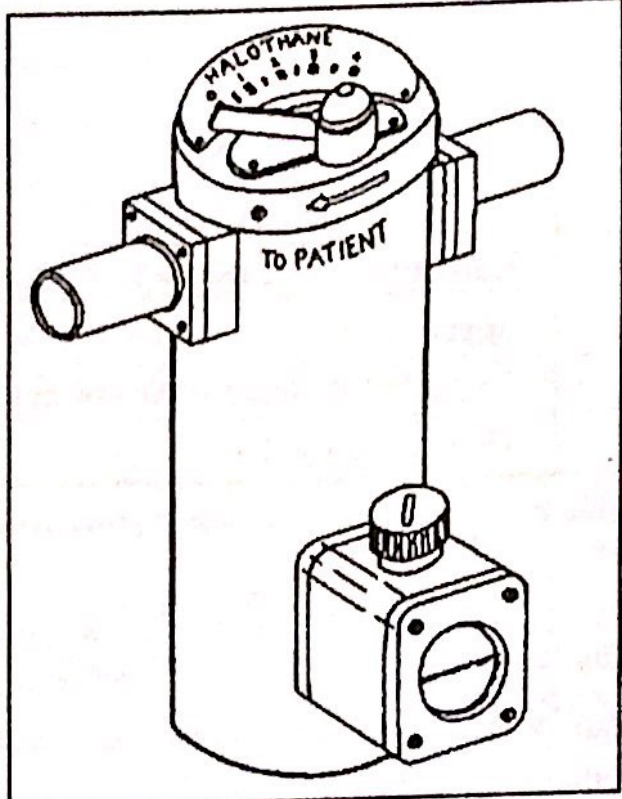

Fig 11: Showing the Oxford miniature vaporizer

rocuronium, sevoflurane are to be used. A large number of cases were paediatric anesthesia and paediatric surgeries.

Boyle's Machine with OMV (Oxford Miniature vaporizer) is better. Tri service apparatus is another option. A good OT table (portable) \& OT light are a must. OT sterilization is equally important. CSSD facility was not in proper order.

This type of ambulatory surgery and anesthesia is first of its kind in the medical history of RNAMC. It may not be economical and easy to continue. For major surgeries, Mobile ICU (Air / Ground) is to be arranged, if there is need to transfer the patient peri-operatively. Mobile blood bank will be an intelligent idea if it is feasible. In the OT, Surgical assistants/anesthesia assistants / Scrub sisters were not enough. 


\begin{tabular}{|l|l|l|l|l|l|}
\hline S.No. & Operation & \multirow{2}{*}{ Cases } & \multicolumn{2}{|c|}{ Anaesthesia } \\
\cline { 3 - 5 } & & & G/A & S/A \\
\hline 1. & Circumcision & & 4 & & \\
\hline 2. & Herniotomy & & 2 & & \\
\hline 3. & Splinter removal & & 2 & & \\
\hline 4. & I\&D & & 1 & & \\
\hline 5. & Arthrotomy (septic arthritis) & & & \\
\hline 6. & Vesiculolithomy & & 1 & & \\
\hline 7. & D\&C & & 1 & & \\
\hline 8. & Galactocolectomy & & & \\
\hline 9. & Gynaecomastia excision & & 1 & & \\
\hline 10. & Anal polyp excision & & 1 & & \\
\hline 11. & lipoma neck & & 1 & & \\
\hline 12. & EUA (bleeding P/R) & & 1 & & \\
\hline 13. & Tongue tie release & & & 1 & \\
\hline 14. & Laparotomy for twisted ovarian cyst & & & 1 & \\
\hline 15. & appendicectomy & & & 1 & \\
\hline 16. & Excision of Hematoma anal region & & & & \\
\hline 17. & Herniorraphy (LIH) & & & \\
\hline
\end{tabular}

Table 2: Showing following surgical procedures were performed at Surkhet Medical Camp

\section{Reference:}

1. Van de Velde M.: Paediatric anesthesia and sedation in remote location: Acta Anestha. Belg 2001:52:187-190

2. Brimacomb J.R. Keler C. : Airway management outside the operating room. Cur. Opin. Anesthesiology 2002:15:461 - 465

3. Gallagher T.J.Anesthesia outside the operating room. Adv. Anesthesia 4:25:1987
4. Greenberg D.J. Romanoff ME: Anesthesi outside of the operating room. page 302.

5. Ronald AMackenzie et al: Anesthesia at remok location: RD. Miller Anesthesia 6th Ed. Vol. ? 2003

6. Janet M. Van Vlymen and P. Fwhite qutpatient anesthesia: RD. Miller Anesthesia $6 t^{\circ} \mathrm{Ed}$. Vo 2003

7. Carlo Missant and Marc Van De Velde Anesthesia outside the operating room Cur Opin. Anesthesiology 2004:17:323 - 327. 